\title{
LETTER
}

\section{Concerns regarding use of one-tailed tests in the SLED-BD vs. CVVH trial}

\author{
Gordon S Doig* \\ See related research by Schwenger et al., http://ccforum.com/content/16/4/R140
}

In the previous issue of Critical Care, I read with great interest the recent randomized controlled trial comparing sustained low-efficiency dialysis using a single-pass batch dialysis system (SLED-BD) with continuous veno-venous hemofiltration $(\mathrm{CVVH})$ [1]. I congratulate the authors on their undertaking but have serious concerns regarding the majority of their analysis. After each table at the end of the paper, the authors report the use of a 'one-tailed Wilcoxon test' to assess continuous outcomes. I do not believe this use is appropriate.

As the authors themselves remark, this clinical trial represents the first reasonably large trial of SLED-BD versus CVVH. Since this is the case, it is inappropriate to postulate a one-tailed hypothesis for any continuous outcomes. For example, given the available evidence, the possibility of increased intensive care unit stay or ventilator time attributable to SLED-BD cannot be excluded. Thus, a one-tailed hypothesis is not appropriate.

To convert the results reported from using a onetailed test to those using a two-tailed $P$ value, the onetailed $P$ value should be doubled. For example, the $P$ value reported in Table 3 for days of mechanical ventilation (one-tailed $P=0.047$ ) should be adjusted to a two-tailed $P$ value of 0.094 . Similarly, all other $P$ values obtained by using a 'one-tailed Wilcoxon test' should also be doubled.

\section{Authors' response}

Oskar Hoffmann, Vedat Schwenger, Markus A Weigand and Christian Morath

Based on recently reported communications [2,3], our suggestion, at least with respect to costs, practicability, heparin consumption, and bleeding risk, was that the SLED technique is superior to CVVH. This - rather than to test whether SLED is equivalent to CVVH - was the objective of our hypothesis. In consequence of this onesided question, we strictly used one-tailed statistical tests [1]. However, the tests used were illustrated adequately and a reader has no problem identifying the use of onesided tests. In addition, the study was not aimed to fit the criteria for an equivalence study. Therefore, to use onesided tests for several parameters and two-sided tests for others remains arbitrary. Nevertheless, if the reader considers this way of analysis to be inadequate, he can simply double the $P$ values in order to support his own assessment of the results.

\section{Abbreviations}

$\mathrm{CWVH}$, continuous veno-venous hemofiltration; SLED, sustained low-efficiency dialysis; SLED-BD, sustained low-efficiency dialysis using a single-pass batch dialysis system.

\section{Competing interests}

The author declares that he has no competing interests.

Published: 14 September 2012

*Correspondence: gdoig@med.usyd.edu.au

Northern Clinical School Intensive Care Research Unit, University of Sydney, Pacific Highway, St Leonards, Sydney, NSW 2065, Australia

\section{References}

1. Schwenger V, Weigand MA, Hoffmann O, Dikow R, Kihm LP, Seckinger J, Miftari N, Schaier M, Hofer S, Haar C, Nawroth PP, Zeier M, Martin E, Morath C: Sustained low efficiency dialysis using a single-pass batch system in acute kidney injury - a randomized interventional trial: the REnal Replacement Therapy Study in Intensive Care Unit PatiEnts. Crit Care 2012, 16:R140.

2. Kielstein JT, Kretschmer U, Ernst T, Hafer C, Bahr MJ, Haller H, Fliser D: Efficacy and cardiovascular tolerability of extended dialysis in critically ill patients: a randomized controlled study. Am J Kidney Dis 2004, 43:342-349.

3. Kumar VA, Craig M, Depner TA, Yeun JY: Extended daily dialysis: a new approach to renal replacement for acute renal failure in the intensive care unit. Am J Kidney Dis 2000, 36:294-300.

doi:10.1186/cc11490

Cite this article as: Doig GS: Concerns regarding use of one-tailed tests in the SLED-BD vs. CVVH trial. Critical Care 2012, 16:448. 